\title{
Avaliação do serious game Immuno Rush sobre Imunologia
}

\section{Cristiane Tolentino Machado}

Pós doutoranda da Faculdade de Psicologia e de Ciências da Educação, Universidade de Coimbra, Professora Associada do Departamento de Ciências Básicas, Universidade Federal dos Vales do Jequitinhonha e Mucuri cristiane.tolentino@gmail.com

Ana Amélia Carvalho

Professora Catedrática na Faculdade de Psicologia e de Ciências da Educação, Universidade de Coimbra anaameliac@fpce.uc.pt

\section{RESUMO}

Os conceitos de imunologia são complexos e muitas vezes difíceis de se compreender. Este artigo reporta as percepções e reflexões de usuários que jogaram o jogo sobre Imunologia. O Immuno Rush foi criado por pesquisadores da Universidade de São Paulo em parceria com o Manifesto Games em 2016. Trata-se de um jogo para jovens e adultos que parte de uma estratégia defensiva para apresentar os elementos do sistema imunológico humano e o seu funcionamento no combate às infecções. Os resultados apontam para uma boa aceitação do Immuno Rush entre os jogadores que consideraramno como uma forma divertida e motivadora para se apresentar os conteúdos de Imunologia. Por fim, também se apresentam sugestões para se enriquecer o jogo. Immuno Rush pode ser utilizado para apresentar o funcionamento do sistema imunológico de uma forma mais atrativa e inovadora.

PALAVRAS-CHAVE: Immuno Rush, Imunologia, jogo digital, serious game.

\section{Immuno Rush serious game assessment on Immunology}

\begin{abstract}
The scientific concepts of human immunology are inherently complicated and often difficult to understand. Immuno Rush was created by researchers from the University of São Paulo in partnership with the Manifesto Games in 2016. It is a game designed for young people and adults. The game presents the elements of the human immune system and its function to prevent infections. In this study we reported players perceptions about the Immuno Rush. The results indicated that players positively perceived the Immuno Rush as an interesting and motivating game. The players enjoy playing Immuno Rush, found the game innovative and funny. In addition, some suggestions to enrich the game are presented. Immuno Rush appears to be a useful tool to present the immune system in a more attractive way.
\end{abstract}

KEY-WORDS: Immuno Rush, Immunology, digital game, serious game.

\section{INTRODUÇÃO}

O sistema imunológico é crucial para o organismo humano, sendo constituído por células e elementos moleculares que desempenham importantes funções como, por exemplo, a de evitar que o corpo seja tomado por infecções. Entretanto, os termos e fenômenos imunológicos são algumas vezes abstratos e de difícil compreensão, como as complexas interações celulares e moleculares envolvidas no seu funcionamento (Raimondi, 2016). 
Os jogos educativos combinam características de jogabilidade com conteúdo para apoiar a aprendizagem ativa e autêntica ao fornecerem experiências concretas e diretas para evocar a motivação e facilitar a compreensão (Clark; Tanner-Smith; Killingsworth, 2016; Jabbar; Felicia, 2015; Wouters et al., 2013). Ao serem bem planejados, os jogos exigem que os jogadores reflitam sobre o conteúdo aprendido e as ações tomadas durante o jogo (Morris et al., 2013). Os jogos educativos também são denominados como serious games ou jogos sérios, definidos como jogos digitais que não são projetados principalmente para fins comerciais ou de entretenimento, mas sim para desenvolver nos usuários um conjunto específico de habilidades para fins educacionais ou de treinamento (Annetta et al., 2009; Djaouti; Alvarez; Jessel, 2011; Michael; Chen, 2006).

A motivação é uma característica marcante dos jogos sérios ao fornecerem o conteúdo de uma maneira que estimula os aprendizes a permanecerem envolvidos. Esse "efeito de imersão" dos jogos sérios promove nos jogadores uma maior atenção à tarefa em questão induzindo-os a continuarem jogando (Cain; Piascik, 2015). Jogos bem delineados, no entanto, envolvem experiências com feedback imediato. Nesse cenário, o erro não é apenas aceitável, é esperado. O elemento crucial do feedback é possibilitar que se aprenda com o erro (Fischer et al., 2006, Rosas et al., 2003; Tannahill; Tissington, 2012). Os jogos criam um ambiente onde o esforço e a persistência são recompensados, permitindo ao aprendiz ver a falha menos negativamente e como uma oportunidade adicional para a aprendizagem (Lee; Hammer, 2011).

$\mathrm{Na}$ área da saúde, os jogos sérios podem ser muito úteis na formação dos profissionais, auxiliando-os no treinamento de técnicas e nas simulações de situações clínicas (Kerfoot; Kissane, 2014; Rosser et al., 2017). São também utilizados na educação de pacientes, por exemplo, ao fornecer informações sobre a prevenção de doenças e ser um estímulo para a adesão aos tratamentos (Boyle et al., 2012; Connolly et al., 2012; Drummond et al., 2017; Ohannessian et al., 2016; Savi; Ulbricht, 2008). Os jogos sérios também são eficazes na indução das mudanças comportamentais em vários contextos, como na prevenção do abuso de substâncias químicas (Rodriguez; Teesson; Newton, 2014), na adesão medicamentosa (Kato et al., 2008) e na promoção geral da saúde (DeSmet et al., 2014, 2015). Dessa forma, os jogos sérios são utilizados com sucesso na área da saúde tanto para educar como também para estimular mudanças comportamentais e de atitude. Pelo acima exposto, em face dos vários benefícios do jogos sérios na área da saúde, é elaborada a seguinte questão de investigação: Quais são as percepções dos jogadores sobre o Immuno Rush nos aspectos da motivação, experiência do usuário e conhecimento?

\section{MATERIAL E MÉTODOS O jogo Immuno Rush}

Em 2016, o jogo Immuno Rush foi criado pelos pesquisadores do Centro de Pesquisa em Doenças Inflamatórias (CRID) da Universidade de São Paulo em parceria com o Manifesto Games- estúdio de produção de jogos digitais e apoio da Fundação de Amparo à Pesquisa do Estado de São Paulo (FAPESP) (Figura 1). É um jogo em língua portuguesa, em estilo Tower Defense destinado a jovens e adultos. Pode ser jogado no computador ${ }^{1}$, celular ou tablet, de forma gratuita e disponível no Google Play e App Store-Itunes. Em Immuno Rush, o jogador protegerá o corpo humano atuando como um comandante do sistema imune. Os invasores representados pelos vírus, bactérias, protozoários, fungos e helmintos estão tentando invadir o corpo humano e para impedir a invasão, o jogador terá que elaborar estratégias para a defesa, construindo as torres

\footnotetext{
${ }^{1}$ URL do Immuno Rush para computador http://crid.fmrp.usp.br/jogos/immuno-rush/
} 
representadas pelas células do sistema imune, como macrófagos, neutrófilos, entre outras. Ao avançar no jogo, os invasores tornam-se mais fortes e as células do sistema imune mais potentes. O jogador passa a ter que elaborar estratégias de defesa cada vez mais complexas para destruir os microrganismos e impedir que o corpo seja tomado pela infecção. O jogo apresenta cinco fases em progressivo grau de dificuldade, nomeadamente: a pele, o pulmão, o intestino, o coração e o cérebro. A cada fase surgem novos elementos do sistema imunológico para combater os microrganismos que, por sua vez, tornam-se sucessivamente diversificados e resistentes. $\mathrm{Na}$ fase da Pele, os neutrófilos e macrófagos apresentam-se como células da defesa no combate às bactérias (Figura 2). Durante essa fase, surgem as células dendríticas e as bactérias tornam-se mais numerosas e resistentes. Ao conseguir eliminar os invasores, o jogador passa para a próxima fase: o Pulmão. No Pulmão, apresentam-se os eosinófilos, além dos neutrófilos, macrófagos e células dendríticas. Quanto aos invasores, além das bactérias, estão presentes os vírus, fungos e helmintos (Figura 3). Ao finalizar a fase do Pulmão, vê-se a indicação para a próxima fase: o Intestino. Na fase do Intestino, surgem novos invasores: os protozoários e para combatê-los estão presentes os linfócitos e mastócitos (Figura 4). Ao eliminar os patógenos no intestino, passa-se à próxima fase: o Coração na qual surgem os basófilos que estão envolvidos em processos alérgicos e de hipersensibilidade (Figura 5). A última fase do jogo passa-se no Cérebro, uma das áreas mais importantes do corpo humano, e para impedir a invasão e livrar o organismo das infecções estão presentes os elementos do sistema complemento que facilitam a destruição dos invasores (Figura 6). Ao concluir esta última fase com sucesso, vê-se a mensagem de que a invasão foi impedida. A seguir, as mensagens de conclusão do jogo e de felicitação ao jogador são mostradas.

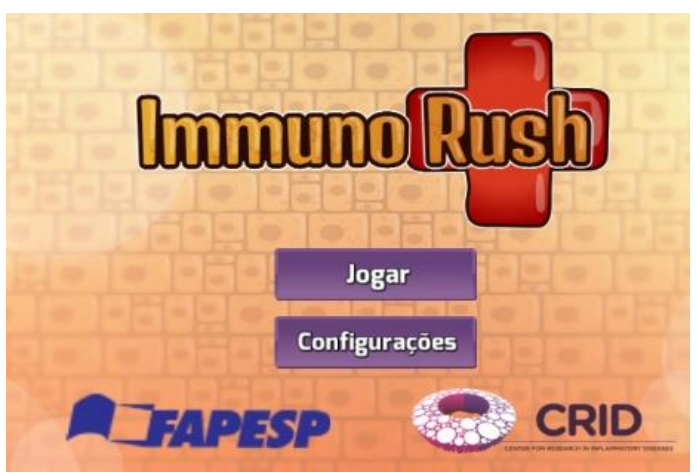

Figura 1 - Página inicial do jogo Immuno Rush

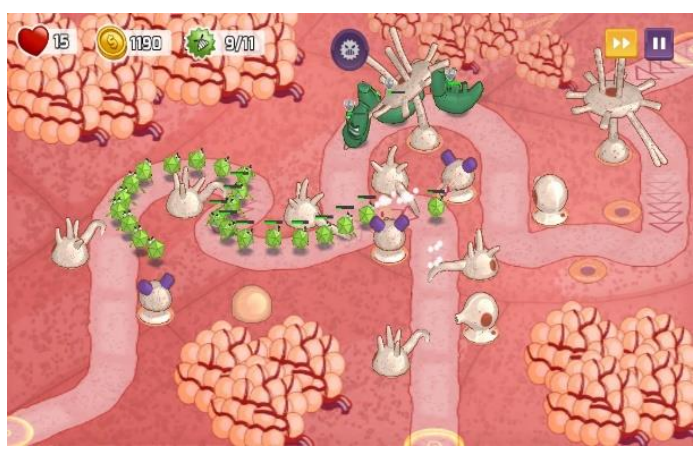

Figura 3 - Os invasores no Pulmão: vírus e helmintos. Os eosinófilos surgem nesta fase

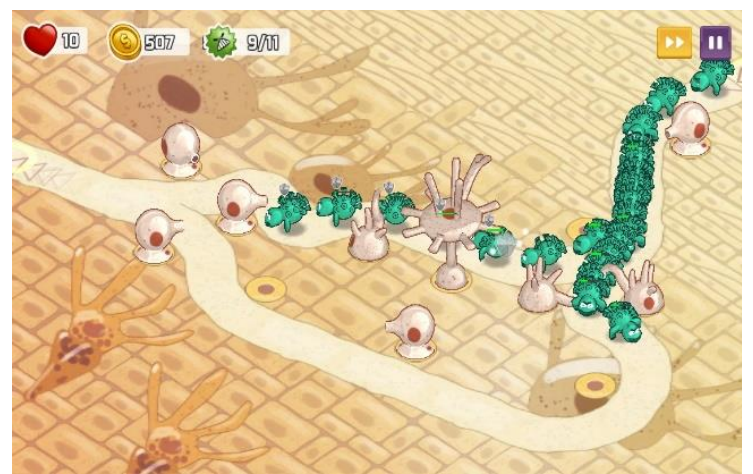

Figura 2 - Na Pele, os neutrófilos, macrófagos e células dendríticas combatem as bactérias

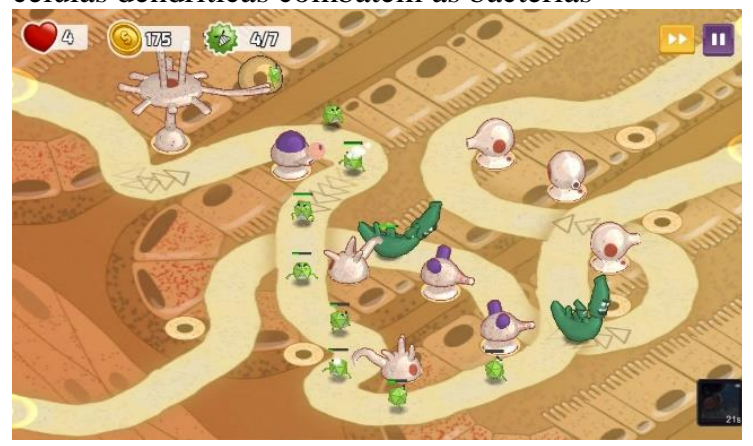

Figura 4 - Helmintos e linfócitos estão presentes no Intestino 


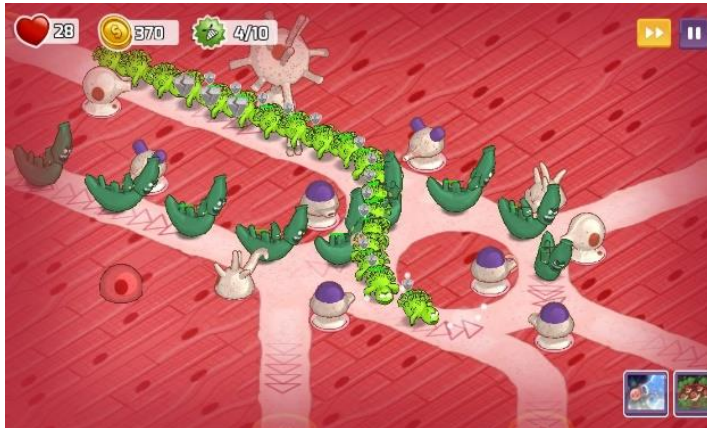

Figura 5 - Fase do Coração com linfócitos, mastócitos e basófilos para a destruição dos invasores

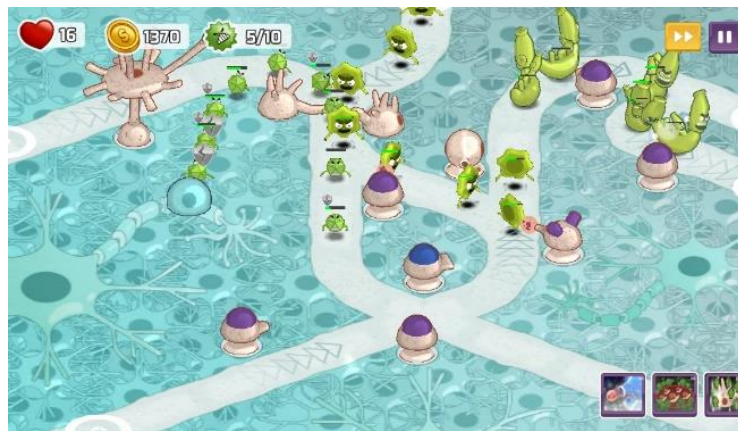

Figura 6 - Fase do Cérebro com a presença de vírus, protozoários e helmintos

Em cada fase, o jogador usufrui das vidas (coração), dos recursos disponíveis (moeda) e visualiza o número de ondas inimigas (ícone verde). Esses ícones estão localizados na parte superior esquerda da tela. Se os inimigos percorrerem todo o trajeto no interior do órgão sem serem destruídos, as vidas irão diminuindo. Os recursos são utilizados para adquirir mais células e também para torná-las mais potentes. À medida que os invasores são destruídos, os recursos aumentam.

A fim de avaliar o jogo Immuno Rush, solicitou-se a participação de voluntários para jogar. Os participantes jogaram o jogo sem nenhuma assistência ou intervenção das pesquisadoras. A seguir, auscultaram-se os jogadores e a eles foi solicitado que comentassem suas percepções e reflexões acerca do jogo através de um questionário que visou avaliar se o jogo (i) consegue motivar os jogadores para a aprendizagem e se (ii) proporciona uma boa experiência.

\section{$O$ instrumento de recolha de dados}

O questionário foi constituído por três partes: a primeira parte de caracterização, contendo perguntas como: nome, escolaridade, frequência com que joga e preferências quanto ao tipo de jogo e plataforma.

A segunda parte integra o modelo proposto por Savi e colaboradores (2010) para avaliar jogos educacionais, tendo como referência a avaliação de programas de treinamento de Kirkpatrick, as estratégias motivacionais do modelo ARCS de Keller, a área de experiência do usuário e a taxonomia de objetivos educacionais de Bloom. Pretende-se analisar as percepções dos jogadores, relativamente a três dimensões: motivação, experiência do usuário e conhecimento, tendo 33 itens. Utilizou-se uma escala de tipo Likert que variava de 1- Discordo Totalmente a 5- Concordo Totalmente, para as respostas. Na Tabela 1 apresenta-se a estrutura desta parte do questionário, indicando para cada dimensão, as subdimensões e o número de itens.

Tabela 1 - Perceções dos jogadores sobre jogos educacionais: dimensões e subdimensões (Savi et al.,

\begin{tabular}{|c|c|c|}
\hline \multicolumn{2}{|c|}{$2010)$} \\
\hline Dimensões & Subdimensão & Número de itens \\
\hline \multirow{3}{*}{ Motivação } & Atenção & 1 \\
\cline { 2 - 3 } & Relevância & 2 \\
\cline { 2 - 3 } & Confiança & 6 \\
\cline { 2 - 3 } & Satisfação & 5 \\
\hline \multirow{2}{*}{ Experiência do usuário } & Imersão & 5 \\
\cline { 2 - 3 } & Desafio & 3 \\
\cline { 2 - 3 } & Habilidade/competência & 5 \\
\cline { 2 - 3 } & Divertimento & 5 \\
\hline
\end{tabular}




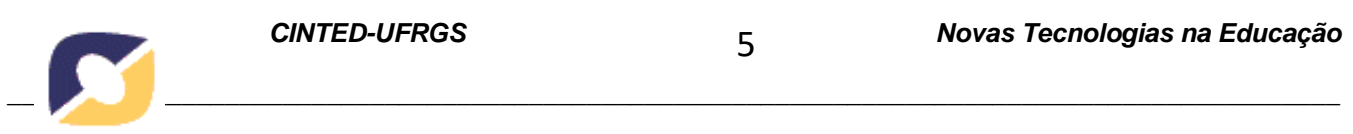

\begin{tabular}{|c|c|c|} 
Conhecimento & ---- & 3 \\
\hline \multicolumn{2}{l}{ Fonte: Instrumento de Savi e colaboradores (2010) }
\end{tabular}

Por fim, a terceira parte apresentava questões de resposta aberta para que apontassem sugestões para melhorar o jogo e se o jogo facilitou na compreensão do tema abordado (Adjed et al., 2017; Barbosa Neto, 2011; Raimondi, 2016; Savi et al., 2010; Su, Cheng, Lin, 2014). O questionário foi disponibilizado no formulário do Google Drive.

\section{Tratamento dos dados do questionário}

Foi realizada a análise de percentagem para as questões fechadas do questionário. As respostas foram agrupadas por: discordância, nem concorda nem discorda ou concordância. As respostas abertas foram analisadas e categorizadas segundo a técnica de análise de conteúdo (Amado, 2014; Coutinho, 2013).

\section{RESULTADOS}

\section{$O$ perfil dos jogadores}

Os 12 participantes responderam a um questionário sobre suas preferências sobre os jogos digitais e percepções em relação ao jogo Immuno Rush.

Dentre os participantes, $54 \%$ eram do sexo masculino e $46 \%$ do sexo feminino com idades entre os 19 e os 44 anos. Alguns participantes tinham o ensino médio completo (34\%) e a maioria (66\%) possuía o ensino superior completo. Os participantes com ensino superior completo eram de diferentes áreas do conhecimento, como administração de empresas (25\%), ciências biológicas (25\%), comunicação social (12,5\%), enfermagem $(12,5 \%)$, medicina $(12,5 \%)$ e odontologia $(12,5 \%)$. Foi constatado que todos têm pelo menos um dispositivo móvel e que $36 \%$ preferem jogar no celular. Preferem jogos de Aventura (37,5\%), Simulação (25\%), Ação (25\%) e Role Playing Game (RPG) (12,5\%). Dentre os participantes, 27\% disseram não jogar e dentre os jogadores, $36 \%$ jogam pelo menos uma vez na semana e $25 \%$ jogam diariamente. A maioria (60\%) prefere jogar sozinha do que jogar em equipe (40\%). Ao serem questionados em qual plataforma jogaram o Immuno Rush, $75 \%$ jogaram no celular e $25 \%$ no computador.

\section{As percepções dos jogadores sobre o Immuno Rush}

$\mathrm{Na}$ avaliação da percepção do jogo, os participantes posicionaram-se perante as afirmações de cada dimensão, como se apresenta de seguida.

a) Motivação

Todos concordaram que o design da interface do jogo é atraente. Na subdimensão sobre a relevância, 83,4\% concordaram que o conteúdo do jogo é útil e que gostariam de aprender mais sobre o assunto. Todos discordaram que o conteúdo do jogo era abstrato sendo difícil manter a atenção. A maioria (75\%) assinalou que o jogo não era difícil de entender e que não era difícil lembrar dos pontos importantes, sendo que $91,7 \%$ compreenderam o que cada ícone representava no jogo. Na subdimensão sobre a satisfação, a grande maioria dos participantes $(83,4 \%)$ sentiu-se realizada ao completar as etapas e $75 \%$ consideraram que os comentários durante o jogo os ajudaram a sentiremse recompensados pelo esforço. Nesta dimensão, a média obtida foi de 4,16 pontos em 5 pontos, o que reforça a motivação sentida.

b) Experiência do usuário

Relativamente à subdimensão imersão, a maioria (75\%) afirmou não perceber o tempo passar enquanto jogava. Manifestaram indecisão sobre terem perdido a consciência do 
que estava ao seu redor enquanto jogavam $(50 \%)$ e sobre sentir-se mais no ambiente do jogo do que no mundo real $(58,4 \%)$.

Quanto à subdimensão desafio, a grande maioria $(83,4 \%)$ concordou que o jogo é motivador, dá vontade de continuar e os desafios surgem num ritmo apropriado $(75 \%)$. A maioria $(66,6 \%)$ considerou o jogo adequadamente desafiador, não sendo as tarefas nem muito fáceis nem muito difíceis e as suas habilidades melhoraram gradualmente com a superação dos desafios presentes no jogo. Mais de metade dos participantes $(58,4 \%)$ indicaram ter gostado do jogo e não se sentiram ansiosos nem entediados.

Na subdimensão habilidade ou competência, a maior parte dos participantes sentiu-se bem sucedida $(58,4 \%)$, competente $(58,4 \%)$ e que estava tendo progresso durante o jogo $(66,7 \%)$. Na subdimensão sobre o divertimento, a grande maioria $(83,4 \%)$ concordou que jogaria o jogo novamente. A maior parte dos participantes discordou em ter torcido para o jogo acabar logo $(75 \%)$ e discordou que o jogo era meio parado $(66,7 \%)$. Metade dos participantes $(50 \%)$ considerou que havia algumas coisas no jogo que causavam irritação e conseguiu chegar ao final do jogo. A pontuação média na dimensão da experiência do usuário foi de 3,58 pontos.

c) Conhecimento

A grande maioria compreendeu com facilidade como jogar o Immuno Rush $(91,7 \%)$, compreendeu melhor o conteúdo de Imunologia após ter jogado o jogo $(83,3 \%)$ e recomendaria o jogo a um amigo $(83,4 \%)$. A média obtida foi de 4,07 pontos.

Quanto à recomendação de melhorias para o Immuno Rush, os jogadores abordaram os seguintes aspectos:

a) aumentar as possibilidade de defesa (33\%): "Menos rapidez nos patógenos, em algumas fases é tão rápido que levamos muito tempo para conseguir passar"; "Não haver tantos vírus num só nível"; "A última fase é mega difícil, poderia ter dicas ou mais espaços para inserir as defesas"; "Recomendaria livre arbítrio na colocação das torres para dinamizar o jogo".

b) tornar as instruções do jogo mais explicativas (16\%): "ser mais explicativo na forma de jogar"; "tornar as instruções do jogo mais claras".

c) aumentar o tamanho dos caracteres (16\%): "aumentar o tamanho das letras"; aumentar a fonte das letras para facilitar a leitura no celular".

d) acrescentar novas fases (8\%): "recomendo mais fases em outras partes do corpo".

e) melhorar a compatibilidade com as plataformas (8\%): “...não funcionou em alguns browsers".

f) apresentação do conteúdo (8\%): "apresentar a informação educacional mais intuitiva e clara”.

Ao serem questionados se o jogo os ajudou na melhor compreensão de Imunologia, todos concordaram com o seu caráter educativo e destacaram que as fases do jogo:

a) promoveram um melhor entendimento do conteúdo (100\%): "Sim, devido às explicaçōes"; "...com certeza ajudou bastante; "Sim, fiquei a conhecer como nosso corpo combate os virus".

b) facilitaram a aprendizagem de novos termos e do funcionamento do sistema imunológico (33\%): "Sim, aprendi novos termos, entendi melhor o que é imunologia e como as defesas do corpo são importantes para nos manter saudáveis".

c) promoveram a associação da imagem com a respectiva função dos elementos do sistema imunológico e dos microrganismos (16\%): "Pois visualizando a imagem 
de cada um e tendo a respectiva função ao mesmo tempo, ficou mais fácil de perceber o sistema imunológico".

d) apresentaram informações básicas e diretas (16\%): "Dá a conhecer alguns componentes da defesa imunológica do corpo humano".

e) tornaram o assunto interessante e acessível (16\%): "O jogo é bem informativo e dinâmico, tem conceitos importantes sobre imunologia”; "Achei o assunto bem interessante".

f) estimularam a aplicar as informações apresentadas sobre os componentes do sistema imunológico e patógenos para vencer o jogo (8\%): "Sim, para saber como vencer tive que entender sobre quais eram os agentes e quais as defesas eficazes contra eles".

g) possibilidade de jogar sem necessariamente ter conhecimentos prévios sobre o tema e de ao jogar adquirir tais conhecimentos (8\%): "permite que qualquer pessoa que jogar adquira conhecimento sobre esse assunto".

h) despertaram a atenção sobre o tema (8\%): "Sim, prestar mais atenção no assunto".

\section{DISCUSSÃO}

Serious games têm sido usados como métodos muito úteis para melhorar a compreensão e aumentar o interesse nos mais diversos assuntos por proporcionarem uma experiência divertida e interativa. No presente estudo, foram avaliadas as percepções dos jogadores em relação ao Immuno Rush, um jogo que integra os conceitos de Imunologia de forma a simular o funcionamento do sistema imunológico humano.

De acordo com os resultados apresentados, o jogo Immuno Rush despertou a motivação da grande maioria dos participantes que percebeu a relevância do tema e demonstrou interesse em aprender mais sobre o assunto fora do jogo. Além disso, a grande maioria dos jogadores demonstrou satisfação em jogar, ao completar as fases do jogo e a sentir a recompensa pelo esforço em terminar o jogo.

No que diz respeito à experiência do usuário, a subdimensão da imersão do jogador obteve a menor pontuação. Embora $75 \%$ dos jogadores afirmassem ter perdido a noção do tempo enquanto jogavam. Constatamos que o jogo exige atenção contínua e aumenta a velocidade à medida em que surgem os invasores progressivamente numerosos e resistentes. O jogador fica concentrado no jogo. Durante o jogo, os invasores ficam mais fortes e surgem diferentes células de defesa para destruí-los, de forma a exigir que o jogador elabore estratégias cada vez mais complexas.

No presente estudo, embora o grau de confiança tenha estado relativamente alto sobre a compreensão do jogo, dentre as melhorias sugeridas foram a de aumentar as possibilidades de defesa e tornar mais claras as instruções e os conteúdos do jogo. Uma possibilidade de se tentar minimizar estas dificuldades seria a de se acrescentar ao Immuno Rush o botão de ajuda, no sentido de fornecer mais informações sobre o funcionamento do jogo.

Ainda no que se refere aos aspectos a serem melhorados, os participantes indicaram a falta de compatibilidade com alguns browsers e sentiram algumas dificuldades em vencer determinadas fases do jogo. Um fator que poderia contribuir para a troca de experiências e aumentar a colaboração entre os jogadores seria a de se acrescentar ao Immuno Rush a possibilidade da interação social que permitiria a comunicação entre os jogadores dentro do próprio jogo como ocorre, por exemplo, nos jogos online. Além de facilitar na compreensão dos conteúdos, uma vez que os jogadores poderiam partilhar seus conhecimentos e experiências sobre o jogo. No presente estudo, a maioria dos participantes jogou o Immuno Rush no celular e reportou dificuldades na leitura pois os 
caracteres do jogo eram muito pequenos. Considerando que o jogo Immuno Rush disponível nos celulares seja uma mais valia ao facilitar ao usuário o seu acesso, é oportuno que esteja adequado a estes dispositivos.

O Immuno Rush demonstrou ser um jogo divertido na percepção dos participantes desse estudo, uma vez que tencionaram jogar mais vezes e sugeriram que mais fases fossem adicionadas ao jogo a fim de melhorá-lo. Segundo as percepções dos jogadores, o jogo Immuno Rush torna os conceitos de Imunologia mais compreensíveis, torna mais fácil a associação das imagens dos elementos do sistema imunológico com suas respectivas funções e a dinâmica do jogo permite um melhor entendimento do funcionamento do sistema imunológico no combate às infecções. Tal percepção foi também relatada em outros estudos com jogos digitais sobre Imunologia (Cheng et al., 2014; Raimondi, 2016). No presente estudo, os participantes consideraram que o Immuno Rush permite que o usuário aprenda Imunologia jogando, "permite que qualquer pessoa que jogar adquira conhecimento sobre esse assunto". Além de estimular os jogadores a aplicarem as informações sobre os componentes do sistema imunológico e patógenos a fim de vencer o jogo, "para saber como vencer tive que entender sobre quais eram os agentes e quais as defesas eficazes contra eles", como também foi reportado no jogo Hummunology (Cheng et al., 2014).

\section{CONCLUSÕES}

O Immuno Rush oferece uma oportunidade de se apresentar o funcionamento do sistema imunológico no que diz respeito ao combate às infecções de uma forma dinâmica e capaz de despertar a atenção dos usuários sobre o tema.

Tal como neste estudo, tem-se constatado em outros estudos que os jogadores reconhecem o valor dos serious games na aprendizagem, bem como a sua faceta lúdica e envolvente (Adjedj et al, 2017; Cheng et al., 2014; Raimondi, 2016; Su; Cheng; Lin, 2014; Thiry; Zoucas; Gonçalves, 2010).

Embora existam aspectos a melhorar, como indicamos, o Immuno Rush apresenta grande potencial para ser utilizado para motivar os usuários a conhecerem os aspectos funcionais e estruturais do sistema imunológico humano.

\section{AGRADECIMENTOS}

Aos participantes do estudo. Ao CEIS20 e ao LabTE da Universidade de Coimbra pelo fomento à pesquisa.

\section{REFERÊNCIAS BIBLIOGRÁFICAS}

ADJED, J.; DUCROCQ, G.; BOULETI, C.; REINHART, L.; FABBRO, E.; ELBEZ, Y.; FISCHER, Q.; TESNIERE, A.; FELDMAN, L.; VARENNE, O. Medical student evaluation with a serious game compared to multiple choice questions assessment. JMIR Serious Games, [s.1.] , vol. 5, n. 2, p. 1-8, 2017.

AMADO, J. Manual de investigação qualitativa em educação. Coimbra: Imprensa da Universidade de Coimbra, 2014, 427 p.

ANNETTA, L. A.; MINOGUE, J.; HOLMES, S. Y.; CHENG, M. T. Investigating the impact of video games on high school students' engagement and learning about genetics. Computers and Education, [s.1.], v. 53, p. 74-85, 2009.

BARBOSA NETO, J. F. Jogos educativos em dispositivos móveis como auxílio ao ensino da matemática. Novas Tecnologias na Educação, [s.1.], v. 11, n. 1, p. 1-10, 2011. 
BOYLE, E. A.; CONNOLLY, T. M.; HAINEY, T.; BOYLE, J. M. Engagement in digital entertainment games: A systematic review. Computers in Human Behavior, [s.l.], v. 28, n. 3, p. 771-780, 2012. doi:10.1016/j.chb.2011.11.020

CAIN, J.; PIASCIK, P. Are Serious Games a Good Strategy for Pharmacy Education? American Journal of Pharmaceutical Education, [s.1.], v. 79, n. 4, p. 1-6, 2015.

CHENG, M.; SU, T.; HUANG, W.; CHEN, J. An educational game for learning human immunology: What do students learn and how do they perceive? British Journal of Educational Technology, [s.1.], v. 45, n. 5, p. 820-833, 2014. doi:10.1111/bjet.12098 CLARK, D. B., TANNER-SMITH, E. E.; KILLINGSWORTH, S. S. Digital games, design, and learning: A systematic review and meta-analysis. Review of Educational Research, [s.1.], v. 86, n. 1, 2016.

CONNOLLY, T. M.; BOYLE, E. A.; MACARTHUR, E.; HAINEY, T.; BOYLE, J. M. A systematic literature review of empirical evidence on computer games and serious games. Computers \& Education, [s.1.], v. 59, n. 2, p. 661-686, 2012. doi: 10.1016/j.compedu.2012.03.004

COUTINHO, C. P. Metodologia de investigação em ciências sociais e humanas: Teoria e prática. Coimbra: Almedina, 2013, 412 p.

DESMET, A.; SHEGOG, R.; VAN RYCKEGHEM, D.; CROMBEZ, G.; DE BOURDEAUDHUIJ, I. A systematic review and meta-analysis of interventions for sexual health promotion involving serious digital games. Games Health Journal, [s.l.], v. 4, n.2, p. 78 -90, 2015. doi: 10.1089/g4h.2014.0110.

DESMET, A.; VAN RYCKEGHEM, D.; COMPERNOLLE S.; BARANOWSKI, T.; THOMPSON, D.; GEERT, C.; POELS, C.; VAN LIPPEVELDE, W.; BASTIAENSENS, S.; VAN CLEEMPUT, K.; VANDEBOSCH, H.; BOURDEAUDHUIJ, I. A meta-analysis of serious digital games for healthy lifestyle promotion. Preventive Medicine, [s.1.], v. 69, p. 95-107, 2014.

DJAOUTI, D.; ALVAREZ, J.; JESSEL, J. P. Classifying Serious Games: The G/P/S Model. In FELICIA. P. (Ed). Handbook of research on improving learning and motivation through educational games: Multidisciplinary approaches. Hershey, PA, USA: IGI Global, 2011. p. 118-136. Disponível em http://doi.org/10.4018/978-1-60960495-0.ch006. Acesso em 16 abril 2018

DRUMMOND, D.; MONNIER, D.; TESNIERE, A.; HADCHOUEL, A. A systematic review of serious games in asthma education. Pediatric and Allergy Immunology, [s.1.], v. 28, p. 257-265, 2017.

FISCHER, M. A.; MAZOR, K. M.; BARIL, J.; ALPER, E.; DEMARCO, D.; PUGNAIRE, M. Learning from mistakes: factors that influence how students and residents learn from medical errors. Journal of General Internal Medicine, [s.1.], v. 21, n. 5, p. 419-423, 2006. Disponível em <https://doi.org/10.1111/j.15251497.2006.00420.x>. Acesso em 16 abril 2018.

JABBAR, A. I. A.; FELICIA, P. Gameplay engagement and learning in game-based learning a systematic review. Review of Educational Research, [s.1.], v. 85, n. 4, 2015. Disponível em http://dx.doi.org/10.3102/0034654315577210 . Acesso em 16 abril 2018. KATO, P. M.; COLE, S. W.; BRADLYN, A. S.; POLLOCK, B. H. A video game improves behavioral outcomes in adolescents and young adults with cancer: a randomized trial. Pediatrics, [s.1.], v. 122, n. 2, p. 305-17, 2008.

KERFOOT, P.; KISSANE, N. The use of gamification to boost residents' engagement in simulation training. JAMA Surgery, [s.1.], v. 149, n. 11, p. 1208-1209, 2014. doi:10.1001/jamasurg.2014.1779

LEE, J. J.; HAMMER, J. Gamification in education: What, how, why bother? Academic Exchange Quaterly, [s.1.], v. 15, n. 2, p. 1-5, 2011. 
MICHAEL, D.; CHEN, S. Serious games: Games that educate, train, and inform. Boston, USA: Thomson Course Technology. 2006. 287 p.

MORRIS, B. J.; CROKER, S.; ZIMMERMAN, C.; GILL, D.; ROMIG, C. Gaming science: the "gamification" of scientific thinking. Frontiers in Psychology, [s.1.], v. 4, p. 1-16, 2013. Doi 10.3389/fpsyg.2013.00607.

OHANNESSIAN, R.; YAGHOBIAN, S.; VERGER, P.; VANHEMS, P. A systematic review of serious video games used for vaccination. Vaccine, [s.l.], v. 34, p. 4478-4483, 2016.

RAIMONDI, S. L. ImmuneQuest: Assessment of a Video Game as a Supplement to an Undergraduate Immunology Course. Journal of Microbiology \& Biology Education, [s.1.], v. 17, n. 2, p. 237-245, 2016.

RODRIGUEZ, D. M.; TEESSON, M.; NEWTON, N. C. A systematic review of computerised serious educational games about alcohol and other drugs for adolescents. Drug and Alcohol Review, [s.1.], v. 33, p. 129-35, 2014.

ROSAS, R.; NUSSBAUM, M.; CUMSILLE, P.; MARIANO, V.; CORREA, M.; FLORES, P.; GRAU, V.; LAGOS, F.; LÓPEZ, X.; LÓPEZ, V.; RODRIGUEZ, P.;

SALINAS, P. Beyond Nintendo: design and assessment of educational video games for first and second grade students. Computers \& Education, [s.1.], v. 40, n. 1, p. 71-94, 2003. Disponível em <https://doi.org/10.1016/S0360-1315(02)00099-4> . Acesso em 16 de abril 2018.

ROSSER, J.; LIU, X.; JACOBS, C.; CHOI, K.; JALINK, M.; HOEDEMAKER, H. Impact of Super Monkey Ball and Underground video games on basic and advanced laparoscopic skill training. Surgical Endoscopy, [s.1.], v. 31, n. 4, p. 1544-1549, 2017. doi:10.1007/s00464-016-5059-7

SAVI, R.; ULBRICHT, V. R. Jogos digitais educacionais: benefícios e desafios. Novas Tecnologias na Educação, Porto Alegre, v. 6, n. 2, p. 1-10, 2008.

SAVI, T.; VON WANGENHEIM, C. G.; ULBRICHT, V.; VANZIN, T. Proposta de um modelo de avaliação de jogos educacionais. Novas Tecnologias na Educação, Porto Alegre, v. 8, n. 3, p. 1-12, 2010.

SU, T.; CHENG, M.; LIN, S. Investigating the effectiveness of an educational card game for learning how human immunology is regulated. CBE-Life Sciences Education, [s.1.], v. 13, p. 504-515, 2014.

TANNAHILL, N.; TISSINGTON, P.; SENIOR, C. Video games and higher education: what can "Call of Duty" teach our students? Frontiers in Psychology, [s.1.], v. 3, p. 1-3, 2012. Disponível em <https://doi.org/10.3389/fpsyg.2012.00210>. Acesso em 16 abril 2018.

THIRY, M.; ZOUCAS, A.; GONÇALVES, R. Promovendo a aprendizagem de engenharia de requisitos de software através de um jogo educativo. In: XXI Simpósio Brasileiro de Informática na Educação, ISSN: 2176- 4301, João Pessoa - PB, 23 a 26 de Novembro de 2010.

WOUTERS, P. J. M.; VAN NIMWEGEN, C.; VAN OOSTENDORP, H.; VAN DER SPEK, E. D. A meta-analysis of the cognitive and motivational effects of serious games. Journal of Educational Psychology, [s.1.], v. 105, n. 2, p. 249-265, 2013. Disponível em http://dx.doi.org/10.1037/a0031311. Acesso em 16 abril 2018. 